\title{
The pseudo-mitochondrial genome influences mistakes in
} heteroplasmy interpretation

\author{
Ryan L Parr*1, Jennifer Maki ${ }^{1}$, Brian Reguly ${ }^{1}$, Gabriel D Dakubo1, \\ Andrea Aguirre ${ }^{1}$, Roy Wittock ${ }^{1}$, Kerry Robinson ${ }^{1}$, John P Jakupciak ${ }^{2}$ and \\ Robert E Thayer ${ }^{1}$
}

\begin{abstract}
Address: ${ }^{1}$ Genesis Genomics Inc, 1294 Balmoral Street, Thunder Bay, Ontario, P7B 5Z5, Canada and ${ }^{2}$ Biochemical Science Division, National Institute of Standards and Technology, Gaithersburg, MD 20899, USA

Email: Ryan L Parr* - Ryan.Parr@genesisgenomics.com; Jennifer Maki - Jennifer.Maki@genesisgenomics.com; Brian Reguly - Brian.Reguly@genesisgenomics.com; Gabriel D Dakubo - Gabriel.Dakubo@genesisgenomics.com; Andrea Aguirre - Andrea.Aguirre@genesisgenomics.com; Roy Wittock - Roy.Wittock@genesisgenomics.com; Kerry Robinson - Kerry.Robinson@genesisgenomics.com; John P Jakupciak - john.jakupciak@nist.gov; Robert E Thayer - Robert.Thayer@genesisgenomics.com

* Corresponding author
\end{abstract}

Published: 21 July 2006

BMC Genomics 2006, 7:185 doi:10.1/86/147|-2/64-7-185
Received: 19 April 2006

Accepted: 21 July 2006

This article is available from: http://www.biomedcentral.com//47/-2/64/7//85

(c) 2006 Parr et al; licensee BioMed Central Ltd.

This is an Open Access article distributed under the terms of the Creative Commons Attribution License (http://creativecommons.org/licenses/by/2.0), which permits unrestricted use, distribution, and reproduction in any medium, provided the original work is properly cited.

\begin{abstract}
Background: Nuclear mitochondrial pseudogenes (numts) are a potential source of contamination during mitochondrial DNA PCR amplification. This possibility warrants careful experimental design and cautious interpretation of heteroplasmic results.

Results: Here we report the cloning and sequencing of numts loci, amplified from human tissue and rho-zero $\left(\rho^{0}\right)$ cells (control) with primers known to amplify the mitochondrial genome. This paper is the first to fully sequence 46 paralogous nuclear DNA fragments that represent the entire mitochondrial genome. This is a surprisingly small number due primarily to the primer sets used in this study, because prior to this, BLAST searches have suggested that nuclear DNA harbors between 400 to I,500 paralogous mitochondrial DNA fragments. Our results indicate that multiple numts were amplified simultaneously with the mitochondrial genome and increased the load of pseudogene signal in PCR reactions. Further, the entire mitochondrial genome was represented by multiple copies of paralogous nuclear sequences.

Conclusion: These findings suggest that mitochondrial genome disease-associated biomarkers must be rigorously authenticated to preclude any affiliation with paralogous nuclear pseudogenes. Importantly, the common perception that mitochondrial template "swamps" numts loci precluding detectable amplification, depends on the region of the mitochondrial genome targeted by the PCR reaction and the number of pseudogene loci that may co-amplify. Cloning and relevant sequencing data will facilitate the correct interpretation. This is the first complete, wet-lab characterization of numts that represent the entire mitochondrial genome.
\end{abstract}




\section{Background}

The unique maternal inheritance pattern of mitochondrial DNA (mtDNA), its small genome size, accelerated mutation rate, lack of recombination, and multiple copy number per cell, in comparison to nuclear DNA, are ideal biological traits for investigating evolution, population genetics and for forensic and medical applications. Thus, the mitochondrial genome has been used as a biosensor for the timing and movement of human populations in antiquity $[1,2]$. MtDNA analysis is routinely used in forensic biology to type biological material when degradation prevents nuclear STR amplification [3]. In addition, the entire mitochondrial molecule has potential medical utility because it can serve as a repository of cancer mutations and as a biosensor indicative of genetic alterations [4-13].

Frequently, identifying legitimate mtDNA mutations is confounded by heteroplasmy, a condition in which wildtype and mutant mitochondrial genomes co-exist in a cell. The interpretation of heteroplasmy can further be confounded by the widespread integration of portions of the mitochondrial genome into the nuclear genome [14,15]. These homologous, yet divergent nuclear and mtDNA sequences can be co-amplified in PCR reactions intended to replicate targeted mtDNA sequences only. Although this problem has previously been considered to be muted because of the high copy number of mtDNA over corresponding nuclear loci, caution is warranted [16]. For example, there are specific regions of the mitochondrial genome that have corresponding nuclear mitochondrial pseudogenes (numts) distributed across multiple chromosomes. Hence, there are regions of the mitochondrial genome that have a high nuclear copy number, which are not completely "swamped" during amplification. We report that some heteroplasmies detected in prostate cancer samples are a result of co-amplification of these multiple loci.

A large number of manuscripts addressing errors related to the interpretation of mtDNA and mtDNA heteroplasmy has been published [17-25]. Notably not all these errors are due to pseudogene co-amplification; however, mistakes from pseudogenes may increase with improved sequencing methods and highly sensitive re-sequencing microarray technologies that have a lower detection limit than traditional sequencing and which readily detect lowlevel heteroplasmy $[11,26]$. In some cases, if the heteroplasmy is inherited, it substantially increases the power of mutation detection, which becomes an important aspect since heteroplasmy has been reported as an early indication of disease [27-31]. In addition, if the disease process invokes mitochondrial depletion, this could increase nuclear pseudogene signal in reactions as a result of reduced mitochondrial genome copy number [32]. Loss of mitochondria has been described in several human cancers [33-36]. As well, the number of mitochondria and mtDNA copy number vary for different cell types [37-39]. These important matters relating to sequence interpretation have been generally neglected, in part, due to the lack of numt reference material, which would help investigators determine the relevance of detected mtDNA sequence variations. Hence, the need to validate somatic mitochondrial mutations is a pressing one.

Heteroplasmic issues have already complicated data obtained from other species. For example, in elephant hair, low mtDNA content is the reason why numts were co-amplified and misinterpreted as authentic mtDNA. In contrast, numts were not detected in DNA derived from elephant blood due to the presence of mitochondria-rich platelets [40]. Moreover, the hominid, Gorilla, is well known for significant numt interference with mitochondrial sequences, highlighting the need for diligence when interpreting human mtDNA heteroplasmy [41]. Not surprisingly, the effort for using mitochondrial cytochrome $\mathrm{c}$ oxidase as a primate "barcode" is plagued by numt amplification as well [42].

Further, laser capture microscopy has improved the ability to separate and analyze cancer cells, but because of the decreased amounts of sample DNA, many primer pairs are required to obtain a robust amplification of the entire mitochondrial genome [43]. Moreover, a sufficient number of cells must be captured to avoid incorporation errors associated with low template quantity [44]. This will also be relevant to studies that use formalin-fixed paraffin embedded samples [45]. The use of many primers means that smaller amplicons will be synthesized translating into a higher risk of co-amplification of numts and the potential misinterpretation of heteroplasmic calls.

There is limited in silico and wet-lab evidence indicating that fragments of the human mitochondrial genome are embedded in the nuclear DNA archive [46-50]. These findings emphasize the critical need to minimize erroneous interpretation of heteroplasmy, a vital necessity for precise forensic discrimination, evolutionary studies, and potential diagnostics. We provide evidence of numts for the entire mitochondrial genome by the amplification, cloning, and identification of numts from rho-zero $\left(\rho^{0}\right)$ cells and clinical cancer specimens. Here we present results from overlapping primers, which co-amplified nuclear embedded, paralogous mitochondrial sequence. Surprisingly, our data shows a relatively small number (when compared to hypothetical sequence information obtained from BLAST searches) of multiple nuclear loci that co-amplify with the mitochondrial genome. These findings demonstrate that accurate interpretation of heteroplasmy not only requires careful primer design and testing, but also indicates that a compendium of the sequence 


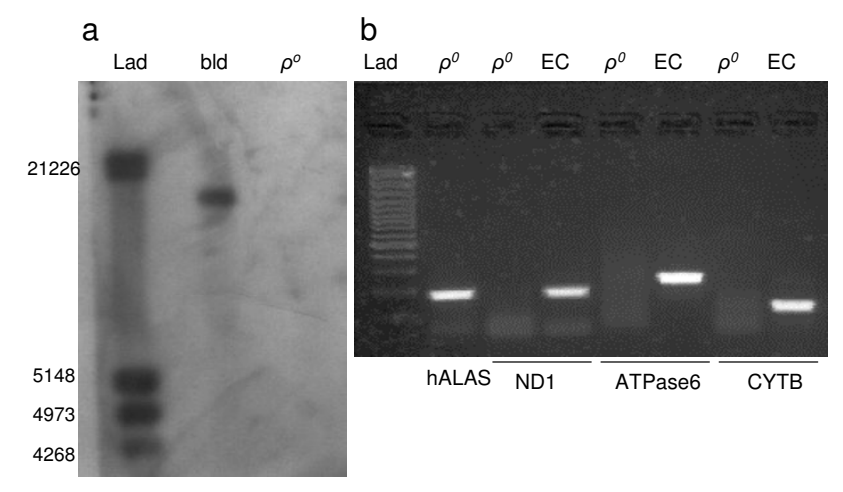

\section{Figure I}

0 cells do not contain mtDNA. a. Southern blot analysis of total DNA extracted from blood (bld) and $\rho 0$ cells and probed with a full length mtDNA probe. Note the absence of hybridization to $\rho 0$ extracts. Lad is a DIG-labeled DNA molecular weight marker III (Roche). b. PCR amplification of cDNA from $\rho 0$ and epithelial cells (EC). Note the amplification of $\rho 0 \mathrm{cDNA}$ with primers to the nuclear gene hALAS, whereas primers to NDI, ATPase6, and CYTB failed to amplify $\rho 0 \mathrm{cDNA}$, although they all amplified cDNA from EC. Lad is a 100bp DNA size standard (Fermentas life sciences).

information from multiple-copy number numts is an important reference tool that will facilitate correct mtDNA interpretation and support reliable mitochondrial genome sequencing data.

\section{Results}

\section{$\rho^{0}$ cells lack mtDNA}

Rho-zero cells were evaluated for the presence of mtDNA. To ensure that total DNA extracted from $\rho^{0}$ cells were indeed devoid of mtDNA, we first performed Southern blot analyses on DNA extracts from $\rho^{0}$ cells. Blood was used as a positive control. No full length mitochondrial genome signal was observed in $\rho^{0}$ lanes when the blots were probed with mtDNA-specific probes (Figure 1a). We next performed PCR on the DNA extracts with primers specific to the mitochondrial coding regions. Again, there were no amplifications observed in the $\rho^{0}$ templates,

Table I: Sequences of four primer sets used in RT-PCR.

\begin{tabular}{ll}
\hline Designation & \multicolumn{1}{c}{ Primer sequence (5'-3') } \\
\hline hALASF & CCACTGGAAGAGCTGTGTGA \\
hALASR & ACCCTCCAACACAACCAAAG \\
NDIF & GAGCAGTAGCCCAAACAATC \\
NDIR & GGGTTCGGTTGGTCTCTGCTAG \\
ATP6F & CCATAAAATTATGAGCGGGCACAGTGATT \\
ATP6R & GGAAGGTTAATGGTTGATATTGCTAGG \\
CYTBF & CTAGCAACACTCCACCTCCTAT \\
CYTBR & GTAAGCCGAGGGCGTCTTTGCTTG \\
\hline
\end{tabular}

while DNA isolated from blood was amplified, as expected (data not shown). We used RT-PCR to provide further evidence that $\rho^{0}$ cells are indeed devoid of mtDNA [51]. RT-PCR analysis was performed on RNA samples from $\rho^{0}$ cells and normal human skin tissue (epithelial cells) samples with primers to OXPHOS genes and a nuclear gene (positive control), 5-aminolevulinate synthase (hALAS) (Table 1). Whereas the hALAS primers amplified nuclear targets in template from $\rho^{0}$ and epithelial cells, there was no observable product with mtDNA primers for the $\rho^{0}$ cDNA template (Figure $1 \mathrm{~b}$ ), independently confirming the absence of mtDNA in these cells.

\section{Co-amplification of numts and mtDNA}

Amplification of the complete mitochondrial genome was performed on human formalin fixed and paraffin embedded (FFPE) prostate cancer samples using a set of 34 primers (Table 2). Due to the amount and quality of DNA recovered, the average amplicon size was limited to 625 bp. Surprisingly, 24 (71\%) of the primer sets co-amplified mitochondrial pseudogenes (Figure 2, and data not shown). A similar ratio was previously reported by an independent group using 38 primers $(26 / 38$ or $68 \%)$ [16]. In an effort to fully characterize numts that represent the entire mitochondrial genome, we redesigned the remaining 10 primers to co-amplify nuclear loci. Thus, we amplified template from $\rho^{0}$ cells and subsequently identified (via sequencing) the cloned fragments from the nucleus. A region of the D-loop (base pairs 16211-420 and 15-711) was recalcitrant to co-amplification using our mitochondrial primers. Therefore, two chromosome 17 specific primers were designed to capture this D-loop fragment (Table 2). Hence, a total of 36 primer sets were used to recover the entire mitochondrial genome from the nucleus. The sequences representative of the entire mitochondrial genome are provided as an additional material (additional file 1). Figure 3 is an example of an alignment to rCRS of three numt clones recovered using primer set 1488F/2084R (Table 2). These three clones were recovered form three separate chromosomes (Chr11 NT_009237, Chr5 - NT_006713, and Chr3 NT_005612). Similar alignment of our consensus cloned sequences enabled the assembly of a pseudo-mitochondrial genome (Figure 4).

The following chromosomes were represented in the data: $1,2,3,4,5,7,8,9,11,16,17,20$ and $\mathrm{X}$. The number of paralogous sequences, in some instances, was lower than the number predicted from BLAST searches (Figure 3, 5). We demonstrate that there are only a limited number of multiple copy numts that potentially contribute to a heteroplasmic signal. Subsequently, we systematically inspected heteroplasmic sites observed in sequences from the prostate cancer samples for numt contribution using our cloned $\rho 0$ data as a reference. We discovered false het- 


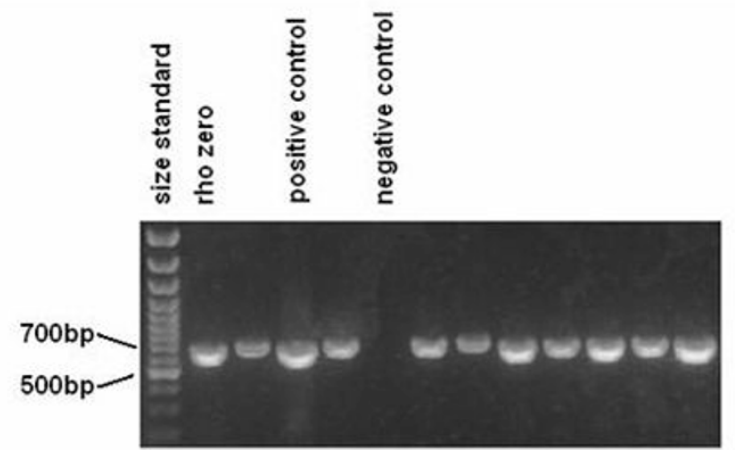

Figure 2

Numts co-amplify from clinical samples. A representative gel picture showing amplification of clinical samples with primers that also amplify $\rho 0$ template is shown. Unlabelled lanes are the clinical samples. Subsequent analysis of sequences from this amplification (see Figure 5) revealed the presence of pseudogene contamination.

eroplasmic sites occurred when there was co-amplification of multiple numt loci with the same nucleotide at that particular site. Base pairs 1709, 1711 and 1719 in one specific amplicon (1488-2084, 16S rRNA) illustrate this point. The amplification of this specific region of the mitochondrial genome also co-amplified numts on chromosomes 3, 5 and 11 (Figures 3, 6). All three chromosomes have an A as opposed to a $\mathrm{G}$, which correspond to mitochondrial positions 1709 and 1719. Using automated DNA sequencing, these multi-copy numts were detected as heteroplasmies at positions 1709 and 1719 (Figure 6). At position 1711, chromosomes 5 and 11 have a $\mathrm{C}$ as does the tissue; however, chromosome 3 has a $\mathrm{T}$. A weak heteroplasmic signal is evident by a minute T peak, but because of the poor detection limit of fluorescent sequencing, this peak is virtually equivalent to background (Figure 6). Heteroplasmic signals were detected for other sites as well. For instance, the primer pair for the amplicon (3230-3893) co-amplified homologous numts on 5 different chromosomes $(2,4,16,17$ and $\mathrm{X})$. This region is evident in the pseudo-mitochondrial genome assembly from our clones (Figure 4).

\section{Multiple numt copies exist in the genome}

To cross-validate our cloned data, we analyzed genomic DNA from $\rho^{0}$ cells, blood, and human placenta using mitochondrial primers that co-amplified nuclear loci in the prostate cancer specimens. In blood and human placenta samples, a single mtDNA amplicon was consistently observed (Figure 7, and data not shown). Although sequence analysis of the prostate specimens detected numts, their signals were below the detection limit of agarose gel electrophoresis. In contrast, several primers con- sistently amplified numts from $\rho^{0}$ cells generating high molecular weight amplifications in addition to the expected mtDNA fragments (Figure 7). These findings confirm the presence of multiple numts loci in the genome and translate into real concern that numts are present in amplifications that produce more that one band or different size amplicons.

\section{Survey of mitochondrial genome mutations associated with disease suggests caution}

Based on our findings that false heteroplasmic sites occurred when there was co-amplification of multiple numt loci with the same nucleotide at that particular site, we compared our cloning data to possible disease associated mutations listed on MITOMAP [52] and common sites were noted. In addition, a BLAST search was performed for these sites and hits held in common between the marker and cloning information were scored as well. Numerous commonalities were noted, which is cause for concern (Table 3).

\section{Discussion}

In this study, we recovered and assembled the entire mitochondrial genome from nuclear loci. Moreover, this "pseudo-mitochondrial genome" involves numts from over half of the human complement of chromosomes, including the $\mathrm{X}$ chromosome. This suggests a widespread allocation of numts in the human nuclear genome. Surprisingly, this distribution was achieved with primers routinely used to amplify mtDNA, yet designed without consideration for numts. Seventy-one percent (24/34) of the primers co-amplified numts in prostate cancer tissue samples. This validates prior suggestions that numts are a potential source of misinformation and serves to illustrate the ease of co-amplification of both mtDNA and nuclear embedded paralogous mitochondrial DNA sequences [16]. Our data demonstrate that contrary to a consensus of opinions that the copy number of the mitochondrial genome "swamps" the signal from numts loci, there are circumstances which favor PCR recovery of numts, such as multiple pseudogene copy number [18]. For instance, heteroplasmic mutations had been associated with late-onset Alzheimer's disease [17,53]; however, these false heteroplasmies resulted from co-amplification of numts $[19,54,55]$. Indeed, human numts perplexed ancient DNA studies as well when it was reported that DNA had been recovered and amplified from a Cretaceous dinosaur bone [56]. This sequence corresponded to a human numt containing cytochrome $b$ sequence [57], probably from reagent or sample contamination.

Direct pseudogene contribution is not always obvious and can confound suggested mtDNA biomarkers. For example, one set of primers in our data set amplifies tRNA ${ }^{\text {leu }}$ and ND1 (3230-3893). Subsequent cloning data 


\section{a}

\begin{tabular}{|c|c|}
\hline 同 RCRS & GACAACCTTAGCCAAACCATTTACCCAAATAAAGTA: \\
\hline NT_009237 & 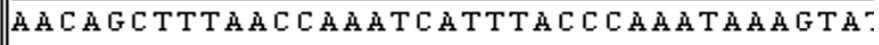 \\
\hline GGML24_GI_GI_A03.ab1 & 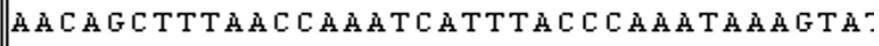 \\
\hline GGN24_GI_GI_B07.ab1 & 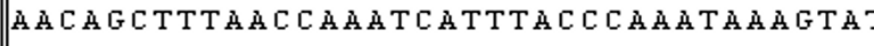 \\
\hline GGMt24_GI_GI_A07.ab1 & 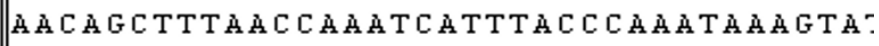 \\
\hline GGML24_GI_GI_B08.ab1 & 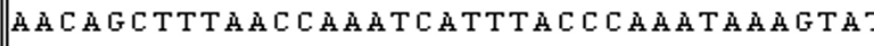 \\
\hline GGML24_GI_GI_B12.ab1 & 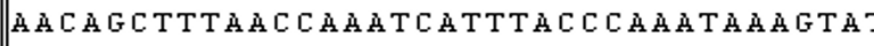 \\
\hline GGN24_GI_GI_B11.ab1 & 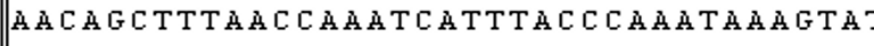 \\
\hline GGM24_GI_GI_B01.ab1 & 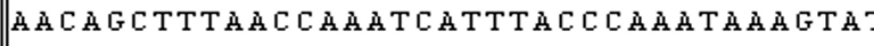 \\
\hline GGN24_GI_GI_Co8.ab1 & 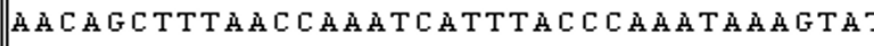 \\
\hline GGN24_GI_GI_D02.ab1| & 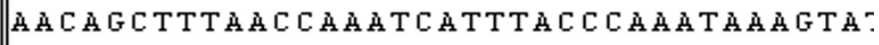 \\
\hline GGM24_GI_GI_A09.ab1 & Ä А С \\
\hline GGU24_GI_GI_C03.ab1| & 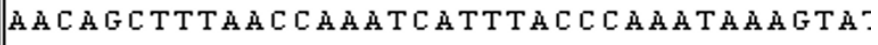 \\
\hline GGU24_GI_GI_A12.ab1 & 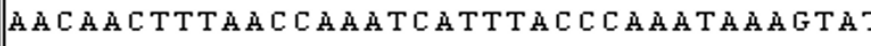 \\
\hline GGMt24_GI_GI_C12.ab1| & AACAGCTTTAACCAAATCATTTACCCAAATAAAGTA: \\
\hline NT_006713 & A \\
\hline GGM24_GI_GI_Co9.ab1| & ÄATAACCTTAACCAAACCATTTACCCAAATAAA \\
\hline GGN24_GI_GI_A04.ab1 & A \\
\hline GGN24_GI_GI_C11.ab1 & 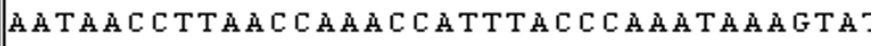 \\
\hline GGM24_GI_GI_B03.ab1 & 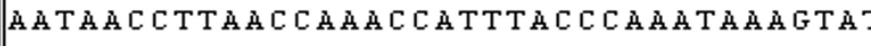 \\
\hline GGM24_GI_GI_B05.ab1 & A \\
\hline GGM24_GI_GI_A10.ab1 | & A \\
\hline GGM24_GI_GI_A05.ab1 & AATAACCTTAACCAAACCATTTACCCAAATAAAGTA: \\
\hline GGM24_GI_GI_D01.ab1| & 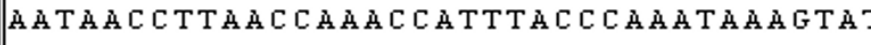 \\
\hline GGM24_GI_GI_C04.ab1| & 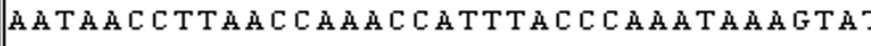 \\
\hline GGM24_GI_GI_B06.ab1| & A \\
\hline GGM24_GI_GI_B10.ab1 & AATAACCTTAACCAAACCATTTACCCAAATAAAGTA: \\
\hline GGM24_GI_GI_B02.ab1 & 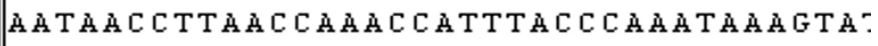 \\
\hline GGN24_GI_GI_C07.ab1 & 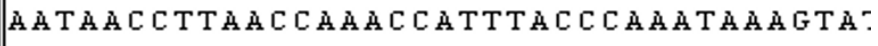 \\
\hline GGM24_GI_GI_Co1.ab1 & 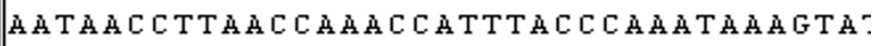 \\
\hline GGN24_Gl_GI_CO6.ab1 & ÄATAACCTTAACCAAACCATTTACCCAAATAAAGTA: \\
\hline NT_005612 & 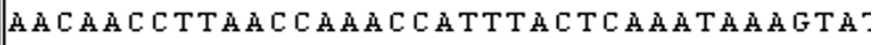 \\
\hline GGM24_GI_GI_C02.ab1| & 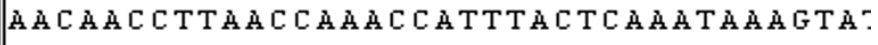 \\
\hline GGM24_GI_GI_D03.ab1| & 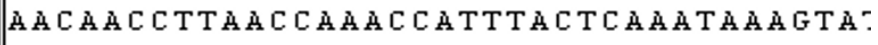 \\
\hline GGN24_GI_GI_C05.ab1 & AACAACCTTAACCAAACCATTTACTCAAATAAAGTA: \\
\hline GGMt24_GI_GI_A08.ab1 & 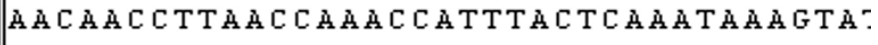 \\
\hline GGM24_GI_GI_C10.ab1 & 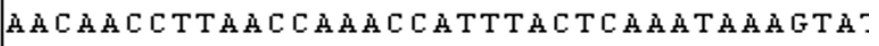 \\
\hline GGN24_GI_GI_B04.ab1 1 & ÄACAAC \\
\hline \multirow{2}{*}{ 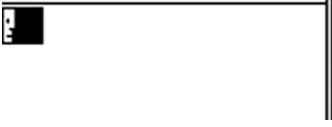 } & 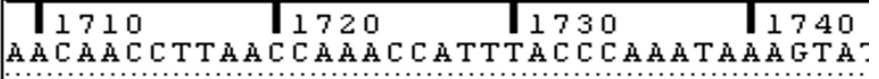 \\
\hline & $\because \bullet \bullet \bullet$ \\
\hline
\end{tabular}

\section{Figure 3}

Example of an alignment of three clones. Example of an alignment of three clones (clones G CII. AI, G C3. Al and G C5.CI) recovered from three chromosomes (Chrl I - NT_009237, Chr5 - NT_0067I3, and Chr3 - NT_0056I2) to the rCRS is shown. 
Table 2: 5' genome location (according to rCRS) and primer sequences for 36 primers including 34 (\#3-36) used to amplify formalin fixed, paraffin embedded tissue. Primers in bold $(1,2)$ indicate chromosome $(C h r) ~ I 7$ specific primers redesigned to capture rest of $D$ loop fragment. The region spanned by I597 I-164I 0 was split into two separate amplicons for the $\rho^{0}$ amplification (I5673-I6009 and 15777-16398).

\begin{tabular}{|c|c|c|c|c|c|c|}
\hline & & Primer Sequence (5'-3') & Mitochondria Position & Chr & Accession Number & Nuclear Position \\
\hline \multirow[t]{2}{*}{ I } & $16319 F$ & ATC GCT CAT GGT AGA TAG CAC & $16319-446$ & 17 & NT 024862.13 & $337395-338087$ \\
\hline & 446R & TGT TAG TTG AGG GGT GAC TGTT & & & & \\
\hline \multirow[t]{3}{*}{2} & 374F & AAT CCA ACT CAA CCA GAG CCC A & $37 \mid-46 I$ & 17 & NT 024862.13 & $338011-338101$ \\
\hline & $78 I R$ & TGA GCT GCA CTA ATG CGT GC & Nuclear Gap & 17 & NT 024862.13 & $338102-338279$ \\
\hline & & & $574-783$ & 17 & NT 024862.13 & $338280-338489$ \\
\hline \multirow[t]{2}{*}{3} & $615 \mathrm{~F}$ & ATG TTT AGA CGG GCT CAC ATC ACC & $651-1247$ & 11 & NT 009237.17 & $9318994-9318400$ \\
\hline & I247R & CAA GAG GTG GTG AGG TTG ATC G & & & & \\
\hline \multirow[t]{2}{*}{4} & I05IF & ACA ATA GCT AAG ACC CAA ACT GGG AT & $1062-1639$ & 11 & NT 009237.17 & $9318585-9318008$ \\
\hline & I644R & CTC CTA AGT GTA AGT TGG GTG CTT TG & $1068-1618$ & 5 & $\overline{\text { NT } 006713.14}$ & $3054|827-3054| 277$ \\
\hline \multirow[t]{3}{*}{5} & I488F & CGT CAC CCT CCT CAA GTA TAC TTC & |497-2049 & 11 & NT 009237.17 & $9318150-9317598$ \\
\hline & $2084 \mathrm{R}$ & TAC AAG GGG ATT TAG AGG GTT CTG TG & |497-2049 & 5 & NT 006713.14 & $3054 \mid 398-30540846$ \\
\hline & & & 1497-2049 & 3 & NT 005612.14 & $2832399-2832340$ \\
\hline \multirow[t]{5}{*}{6} & I938F & AGA GCA CAC CCG TCT ATG TAG CAA & $1938-2612$ & 11 & NT 009237.17 & $9317709-9317035$ \\
\hline & $26 \mid 2 R$ & GGA ACA AGT GAT TAT GCT ACC TTT GCA C & $1938-2612$ & 3 & NT 005612.14 & $283|958-283| 284$ \\
\hline & & & $1939-2612$ & 17 & NT 024862.13 & 3396||$-34028 \mid$ \\
\hline & & & $1940-2612$ & 8 & NT 023678.15 & $902509-901844$ \\
\hline & & & $197 \mid-2612$ & 5 & NT 006713.14 & $30540924-30540284$ \\
\hline \multirow[t]{2}{*}{7} & $24 I 7 F$ & CAC TGT CAA CCC AAC ACA GGC AT & $2402-3078$ & 20 & NT 011362.9 & $20987219-20986564$ \\
\hline & $3 I 0 I R$ & TAG AAA CCG ACC TGG ATT ACT CCG & $2417-3076$ & 17 & NT 024862.13 & $340090-340749$ \\
\hline \multirow[t]{2}{*}{8} & $302 \mathrm{IF}$ & CGC TAT TAA AGG TTC GTT TGT TC & $3070-3673$ & 17 & NT 024862.13 & $340743-341346$ \\
\hline & $3695 R$ & ATC AGG GCG TAG TTT GAG TTT G & & & & \\
\hline \multirow[t]{5}{*}{9} & $3230 \mathrm{~F}$ & GTT AAG ATG GCA GAG CCC GGT AA & $3253-3859$ & 4 & NT 016354.17 & $80880160-80879559$ \\
\hline & $3893 R$ & GTT CGG TTG GTC TCT GCT AGT GT & $3253-3870$ & 2 & NT 005058.14 & $9588|I|-9587524$ \\
\hline & & & $3296-3870$ & 16 & NT 037887.4 & $3360917-3360343$ \\
\hline & & & $3323-3870$ & $x$ & NT 011630.14 & $276|822-276| 28 \mid$ \\
\hline & & & $3347-3870$ & 17 & NT 024862.13 & $341020-341543$ \\
\hline \multirow[t]{2}{*}{10} & $3728 \mathrm{~F}$ & CAT ATG AAG TCA CCC TAG CCA TC & $38|4-439|$ & 17 & NT 010718.15 & $19103293-19103865$ \\
\hline & $44 I 7 R$ & TTT AGC TGA CCT TAC TTT AGG ATG GG & $3816-4391$ & 17 & NT 024862.13 & $34 \mid 489-342064$ \\
\hline \multirow[t]{2}{*}{ II } & $4337 F$ & ATG AGA ATC GAA CCC ATC CCT GAG & $4361-5010$ & I & NT 077913.2 & $43543-44192$ \\
\hline & $5035 R$ & CAT CCT ATG TGG GTA ATT GAG GAG T & & & & \\
\hline \multirow[t]{2}{*}{12} & $4867 F$ & GAC AAA AAC TAG CCC CCA TCT CAA & $4866-5554$ & I & NT 077913.2 & $44048-44736$ \\
\hline & $5646 \mathrm{R}$ & GCT TAA TTA AAG TGG CTG ATT TGC GT & $5169-5632$ & 2 & NT 005403.15 & $6285|66|-62852 \mid 20$ \\
\hline \multirow[t]{2}{*}{13} & $5468 \mathrm{~F}$ & САC GCT АСТ ССТ АСС ТАТ СТС & $5508-6 \mid 24$ & 17 & NT 024862.13 & $343174-343794$ \\
\hline & $6145 R$ & CAG TTG CCA AAG CCT CCG ATT ATG & 55||$-6|2|$ & I & NT 077913.2 & $44693-45303$ \\
\hline \multirow[t]{2}{*}{14} & $5867 \mathrm{~F}$ & CAA TGC TTC ACT CAG CCA TTT TAC C & $5892-6481$ & I & NT 077913.2 & $45074-45663$ \\
\hline & $6482 \mathrm{R}$ & GAC TGC TGT GAT TAG GAC GG & & & & \\
\hline \multirow[t]{2}{*}{15} & $6418 \mathrm{~F}$ & AAC CCC CTG CCA TAA CCC AAT AC & $644 \mid-7056$ & I & NT 077913.2 & $45623-46239$ \\
\hline & $7082 R$ & GAA GCC TCC TAT GAT GGC AAA TAC AG & & & & \\
\hline \multirow[t]{2}{*}{16} & $6911 F$ & TGC AGT GCT CTG AGC CCT AGG ATT & $69|4-752|$ & I & NT 077913.2 & $46097-46704$ \\
\hline & $7554 \mathrm{R}$ & CTT TGA CAA AGT TAT GAA ATG GTT TTT CTA ATA & $6935-7521$ & 5 & $\overline{\text { NT } 034772.5}$ & |804907-|80432| \\
\hline \multirow[t]{2}{*}{17} & $7400 \mathrm{~F}$ & CCC ACC CTA CCA CAC ATT CGA A & $7453-8005$ & I & NT 077913.2 & $46636-47188$ \\
\hline & $8029 \mathrm{R}$ & GGC TTC AAT CGG GAG TAC TAC TCG & & & & \\
\hline 18 & $7829 \mathrm{~F}$ & CGC ATC CTT TAC ATA ACA GAC GAG G & $7853-8472$ & I & NT 077913.2 & $47036-47622$ \\
\hline & $844 I R$ & GTT GGG TGA TGA GGA ATA GTG TAA GG & & & & \\
\hline 17 & $8346 \mathrm{~F}$ & CAACACCTCTTTACAGTGAAATGCCC & $847|-894|$ & I & NT 077913.2 & $47652-48122$ \\
\hline & $8959 \mathrm{R}$ & CGATAATAACTAGTATGGGGAT & & & & \\
\hline 20 & $8814 \mathrm{~F}$ & CCA ACT АTC TAT AAA CCT AGC C & $88 \mid 4-9427$ & I & NT 077913.2 & $47995-48594$ \\
\hline & $94 \mid 3 R$ & GCC TTG GTA TGT GCT TTC TCG TGT & $8816-9375$ & 5 & NT 034772.5 & $\mid 803025-1802466$ \\
\hline 21 & $9247 \mathrm{~F}$ & GCC CAT GAC CCC TAA CAG G & $9268-9845$ & 5 & $\overline{\text { NT } 034772.5}$ & $|802573-180| 994$ \\
\hline & $9868 \mathrm{R}$ & CGG ATG AAG CAG ATA GTG AGG & $9545-9859$ & 7 & NT 079592.1 & $56744603-56744909$ \\
\hline 22 & $97 I I F$ & CTG GGT CTC TAT TTT ACC CTC C & $9730-10300$ & 5 & NT 034772.5 & $1802112-1801539$ \\
\hline & I0285R & GGT AGG GGT AAA AGG AGG GCA & & & & \\
\hline 23 & $10198 \mathrm{~F}$ & CCC GCG TCC CTT TCT CCA T & $10206-10768$ & 5 & NT 034772.5 & $|80| 633-180|07|$ \\
\hline & I0766R & TTA GCA TTG GAG TAG GTT TAG G & & & & \\
\hline 24 & $10696 \mathrm{~F}$ & ССС TAC TAG TCT CAA TCT CCA A & $10694-11509$ & 9 & NT 008470.17 & $2194293-2194999$ \\
\hline & II426R & CTT CGA CAT GGG CTT TAG GGA G & $10751-1 \mid 426$ & 5 & NT 034772.5 & $36678748-36678073$ \\
\hline 25 & $11210 \mathrm{~F}$ & TTC TAC ACC CTA GTA GGC TCC CTT & $11234-11786$ & 5 & NT 034772.5 & $36678265-366777 \mid 3$ \\
\hline
\end{tabular}


Table 2: 5' genome location (according to rCRS) and primer sequences for 36 primers including 34 (\#3-36) used to amplify formalin fixed, paraffin embedded tissue. Primers in bold $(\mathrm{I}, 2)$ indicate chromosome $(\mathrm{Chr}) \mathrm{I} 7$ specific primers redesigned to capture rest of $\mathrm{D}$ loop fragment. The region spanned by $1597 \mid-16410$ was split into two separate amplicons for the $\rho^{0}$ amplification (15673-16009 and 15777-16398). (Continued)

\begin{tabular}{|c|c|c|c|c|c|c|}
\hline \multirow[t]{2}{*}{26} & $11629 \mathrm{~F}$ & AAT CAG CCA CAT AGC CCT CGT AG & $1165 \mid-12205$ & 5 & NT 034772.5 & $36677848-36677294$ \\
\hline & $|223| R$ & GTT AGC AGT TCT TGT GAG CTT TCT CG & $|184|-12206$ & 5 & NT 034772.5 & |7999998-1799633 \\
\hline \multirow[t]{2}{*}{27} & $12096 \mathrm{~F}$ & TCC TAT CCC TCA ACC CCG ACA T & $|2||8-1268|$ & 5 & NT 034772.5 & $3667738|-366768| 8$ \\
\hline & I2709R & GGA AGA TGA GTA GAT ATT TGA AGA ACT G & & & & \\
\hline \multirow[t]{2}{*}{28} & $12528 \mathrm{~F}$ & GAA CTG ACA CTG AGC CAC AAC C & $12550-13070$ & 5 & NT 034772.5 & |799289-1798769 \\
\hline & I3096R & CAA CTA TAG TGC TTG AGT GGA GTA GG & & & & \\
\hline \multirow[t]{2}{*}{29} & $12882 \mathrm{~F}$ & CAT CCT CGC CTT AGC ATG ATT TAT CC & $12908-13493$ & 5 & NT 034772.5 & $36676591-36676006$ \\
\hline & $13516 R$ & GGT CTT TGG AGT AGA AAC CTG TG & $12908-13493$ & 5 & NT 034772.5 & |79893|-|798346 \\
\hline \multirow[t]{2}{*}{30} & I3239F & CGT AGC CTT CTC CAC TTC AAG TC & $13262-13827$ & 5 & NT 023148.12 & $2217633-2218198$ \\
\hline & I385|R & GTT GAG GTC TAG GGC TGT TAG AAG & & & & \\
\hline \multirow[t]{2}{*}{31} & I3354F & TTT ATG TGC TCC GGG TCC ATC AT & |3377-13935 & 5 & NT 023148.12 & $2217748-2218306$ \\
\hline & I3957R & CTA GAT AGG GGA TTG TGC GGT G & & & & \\
\hline \multirow[t]{2}{*}{32} & I3838F & CCC TAG ACC TCA ACT ACC TAA CC & $13895-14454$ & 5 & NT 023148.12 & $2218266-2218823$ \\
\hline & I4458R & GAT GGC TAT TGA GGA GTA TCC T & |4324-14535 & 5 & NT 034772.5 & $36675 \mid 75-36674964$ \\
\hline \multirow[t]{2}{*}{33} & I4339F & ACC CCA TCA TAC TCT TTC ACC C & $\mid 4550-15042$ & 5 & NT 034772.5 & 1797288-1796796 \\
\hline & I5052R & TAG GCC TCG CCC GAT GTG TA & $|4604-| 505 \mid$ & 5 & NT 034772.5 & $36674895-36674448$ \\
\hline \multirow[t]{2}{*}{34} & I497|F & TGG CTG AAT CAT CCG CTA CCT T & $|504|-\mid 5785$ & 17 & NT 024862.13 & $336116-336858$ \\
\hline & I5786R & AAA GGG TAG CTT ACT GGT TGT CC & $15345-15774$ & 5 & NT 023148.12 & $22197 \mid 5-2220144$ \\
\hline \multirow[t]{2}{*}{35} & I5673F & ATC CAA ACA ACA AAG CAT AAT ATT TC & $15672-15994$ & 5 & NT 023148.12 & $2220042-2220364$ \\
\hline & I6009R & AAT TAG AAT CTT AGC TTT GGG TG & & & & \\
\hline \multirow[t]{2}{*}{36} & I5777F & GCT ACC CCT TCA TCA CCT TC & $15785-16388$ & 17 & NT 024862.13 & $336858-337463$ \\
\hline & I6398R & CAA CGG ACC ACT ATC TGA GGG & & & & \\
\hline
\end{tabular}

identified co-amplification of paralogous numts on five chromosomes with this amplicon. Of specific interest are bases 3316, 3496, 3697 and 3796, which are reported as potential disease associated sites [52]. These sites are problematic since the reported base changes are consistent with pseudogene presentation in our data. Further, results from new sequencing technologies have suggested that homoplasmic signals may indeed be heteroplasmic in nature [11]. In addition, the heteroplasmic patterns seen at bps 3697 and 3796 are mirrored by the nuclear pseudogene patterns (Table 3).

Re-examination of the raw data from the above studies could address if the disease mutations are actually due to co-amplified numts. Potential markers must be thoroughly investigated to preclude the inclusion of false mutations in the interpretation of mtDNA mutations. BLAST searches of nuclear pseudogenes belie the possibility of widespread integration and/or replication of these sequences, since primers may amplify homologous numts embedded elsewhere in the genome. Thus, high copy numbers for these nuclear segments can produce potential misleading heteroplasmic signals.

Comparative marker studies require the same conditions and primers for meaningful results. For example, proposed MELAS sites T3250C and T3291C (tRNA ${ }^{\text {leu}}$ ) have paralogous nuclear sites [58-60]. Follow-up work by Akanuma et al. (2000) [61], demonstrate a corollary numt associated site for T3250C, but not T3291C. A BLAST search shows that these competing sequences are on sep- arate chromosomes (17 and 20) indicating comparison of dissimilar data. In addition, the cloning data here identifies similar regions on chromosomes 2, 4 and 17 (Table 3 ). Clearly there are numerous paralogous loci for mitochondrial tRNA ${ }^{\text {leu, }}$, the amplification of which depends on location and homology of primer sets.

Because of this association in our data, we compared our cloning results to the suggested mitochondrial genome disease associated sites listed on MITOMAP [52]. Results suggest that many mutations require meticulous scrutiny because of paralogous nuclear commonalities. Although many of these mutations may well be actual disease markers, the possibility of numt association may confound detection. For example, proposed prostate cancer mutations (G5913A, G5973A and G6081A) are identified, by cloning data, as resident on chromosomes 1 (2 homologous copies) and 17 even though the authors exercised precautionary measures by scanning a database of known nuclear pseudogenes $[49,62]$. A locus on chromosome 6 was identified as a potential co-amplification product, yet chromosomes 1 and 17 were not detected. Co-amplification of numts is primer dependent, which may explain the differences seen here; however, database limitations and the absence of extensive wet-lab numt data obscure the meaning of the marker. Particularly suspicious are those sites which demonstrate heteroplasmy in both normal and disease tissue. This may reflect a consistent pattern of numt amplification, an unintended characteristic of primer design. A subset of the marker work prior to the seminal numt work of Lopez et al. (1994) [14] may need 


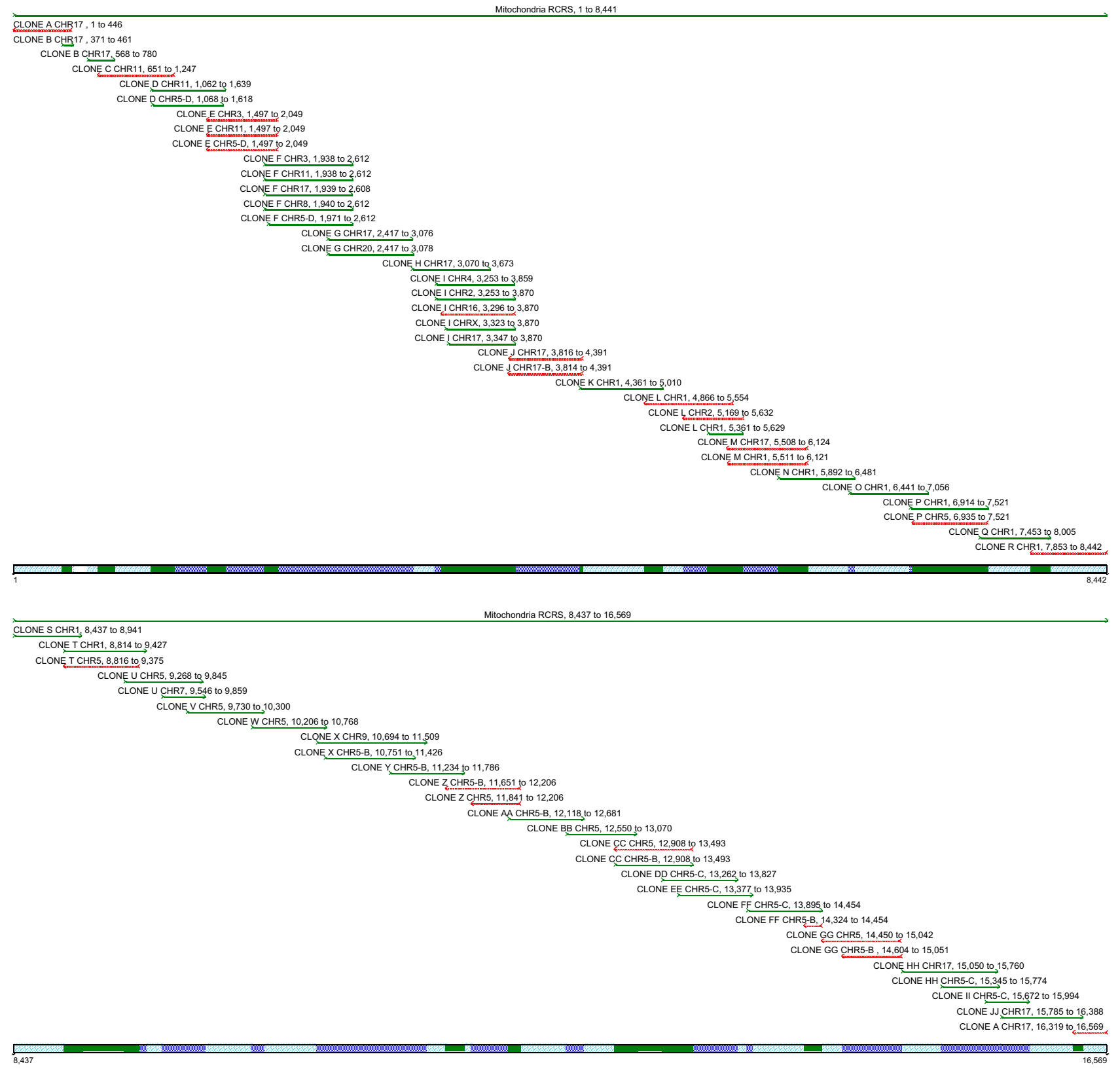

Figure 4

The distribution of numt clones. The distribution of numt clones (based on our primers) across the rCRS reveals regions of the rCRS with multiple numts copies. The pseudo-mitochondrial genome assembled from consensus numt sequences. The distribution of numt clones across the rCRS reveals sites that could be problematic when primers are designed to targets in these regions. Clone name, chromosomal location and rCRS positions are indicated above each clone.

clarification as well. For example, an ND2 lesion associated with Alzheimer's and Parkinson's diseases (G5460T/ A) has modulated $\mathrm{T}$ and A nucleotides. Both mutations are seen in a BLAST search of numts. Moreover, our cloning data also identifies a $\mathrm{G}$ at this point, but not a $\mathrm{T}$, again suggesting the relevance of primer selection; nevertheless, all possible modulations are described in this early work (see Kosel 1994. [63]), yet it remains a primary reference for this lesion.

If the use of mitochondrial DNA and in particular somatic mitochondrial genome mutations has important utility 


\begin{tabular}{|c|c|c|c|}
\hline & & & \\
\hline & & & 1874 \\
\hline NT_0 & & GACT-A-A-TCCC-T-GTACCTTCTGCATA & 17775 \\
\hline NT 006713 & 30541074 & TA-TA-GC-AAGGACT-A-A-CCCC-T-GTACCTTCTGCATAATGAATTAACTAGAAAT & \\
\hline NT 005612 & 2075 & $\triangle C A \wedge C$ & \\
\hline T 0 & & AT & \\
\hline & & & \\
\hline NTE- & & AT & \\
\hline $\mathrm{T}$ & & $\mathrm{T}$ & \\
\hline $\mathrm{NT} 01$ & & & \\
\hline $\mathrm{JT} 01$ & & & \\
\hline 630 & & $\mathrm{~T}$ & \\
\hline & & & \\
\hline NT_0 & & AT & \\
\hline NT 0 & & A-A & \\
\hline & & & \\
\hline & & & \\
\hline IT ( & & AT & 62 \\
\hline T 02 & & & \\
\hline NT 022517 & 346 & CC-TTATACCTTCTGCATAA & 1096 \\
\hline NT 007995 & 90931 & AAAGCA-A-A-A-CCCT-T-ATACCTTCTGCATAA & 3190981 \\
\hline 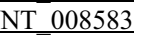 & & & \\
\hline & & & \\
\hline & & & \\
\hline & & CCCT T GTA & \\
\hline NT_008046 & 17314257 & AAA-AA-AC-AAAG-CT-T-A-CCCCTT-ATGCCTTTTGCATAATGAATTAACTAG-AAC & 17314307 \\
\hline
\end{tabular}

\section{Figure 5}

Our primers recovered lower number of paralogous sequences compared to BLAST searches. A BLAST search using the rCRS region covered by the three clones (Figure 3a)returns more numts representative of this region(25)than the three obtained by our cloning data.

and medical merit, much of the data requires critical follow-up from a pseudogene perspective. Amplification of $\rho^{0}$ DNA template with primers to identify and eliminate those which co-amplify nuclear pseudogenes is a vital and necessary procedure [16]. For example, mitochondrial PCR protocols were simultaneously run on clinical samples and nucleic acid recovered from $\rho^{0}$ cells to identify and exclude co-amplification of numts in work by Coskun et al. [64]. Alternatively, data may be screened by amplifi-

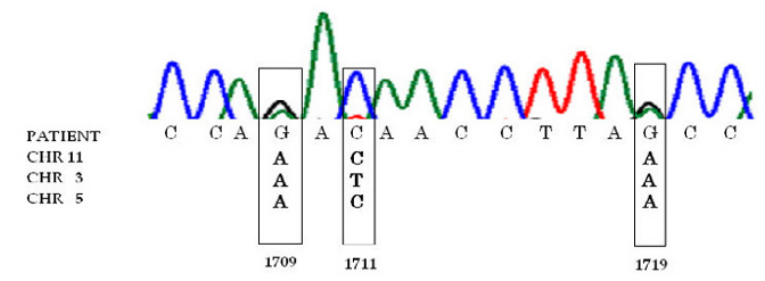

\section{Figure 6}

A "piggyback" effect resulting from chromosomal copy number and shared divergent sites is demonstrated in a patient sample. The chromatogram is from a patient for whom heteroplasmy at positions 1709 and 1719 were later noted tobe homologous to three chromosomes $(3,5$, and II), suggesting a possible co-amplification of numts in this instance. cation and sequencing of $\rho^{0}$ derived DNA and conflicting sites then backed out of actual data generated with identical primers; however, this approach is labor-intensive [43]. Phylogenetic analysis of the data would also help distinguish polymorphisms from authentic mutations [22]. In general, and unfortunately the advice by Parfait et al. has been largely ignored [16].

Our surprising results are not limited to short amplicons, but are also detected in much larger amplicons. For example, the overlapping amplification of chromosome 5 from bp 8816 to 15051 cautions against assuming that long amplicons are pseudogene free. These possibilities and characteristics of the nuclear genome must be considered when using mitochondrial sequence data for population, forensic or disease studies. Although designing and testing primers to avoid co-amplification of numts is a good laboratory practice, compilation of numts representative of the entire mitochondrial genome is valuable to catalog and characterize the overall nuclear burden of these sequences.

\section{Conclusion}

Amplification of overlapping numts paralogous to the mitochondrial genome indicates that co-amplification of nuclear mitochondrial pseudogenes is a real problem for accurate sequence interpretation. Not only is co-amplifi- 


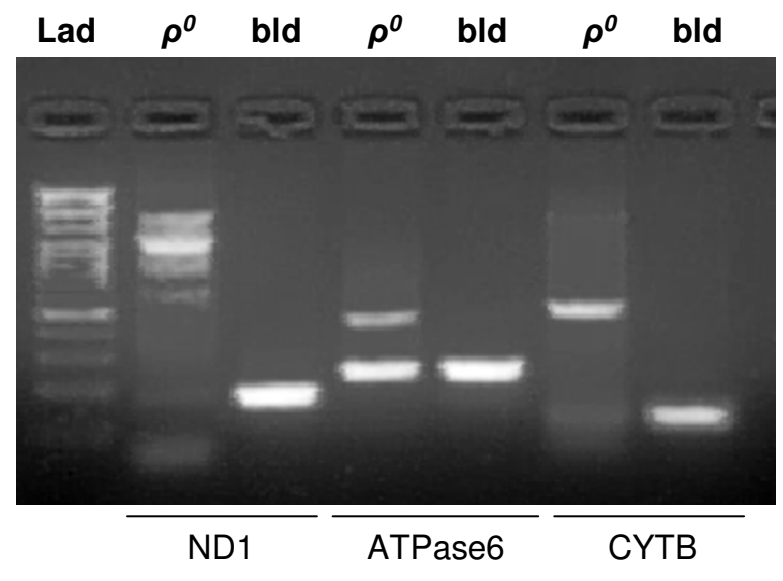

Figure 7

Multiple numt copies are present in the nucleus. PCR amplification of total DNA extracted from $?^{0}$ and blood (bld) cells with primers targeting NDI, ATPase 6 and CYTB genes. In contrast to the single amplicons obtained from blood, template from ?0 contains additional high molecular weight amplicons. Lad is a 100bp DNA size standard (Fermentas life sciences).

cation dependent on the particular amplicon used, but the copy number of these loci is also important. Only certain positions across the mitochondrial genome are associated with multiple copies of numts. Mitochondrial DNA heteroplasmy should be interpreted with caution since they can be the result of nuclear/cytoplasmic co-amplification. Herein, we have demonstrated the robust amplification of numts. This paper is the first to fully sequence the 46 paralogous DNA fragments that represent the entire mitochondrial genome using 36 primer pairs. This is a surprisingly low number, but reveals that only a limited number of paralogous numts are relevant when considering if heteroplasmic call are authentic mutations. Compilation of a complete data set of numt sequences will help others distinguish paralogous nuclear based heteroplasmy in forensic, population and medical applications.

\section{Methods}

\section{Nucleic acid extraction}

All research involving human tissue was approved by the Thunder Bay Regional Health Sciences Centre Ethics Committee in accordance with the Tri-Council Policy Statement for Research Involving Humans http:// www.nserc.ca/programs/ethics.htm. Archived formalin fixed and paraffin embedded (FFPE) prostatectomy samples were laser capture microdissected (LCM) and DNA isolated by proteinase K digestion. DNA was isolated from blood using the UltraClean ${ }^{\mathrm{TM}}$ DNA BloodSpin kit (MO $B I O$ laboratories, Inc). Human placenta DNA was purchased from Sigma-Aldrich (D4642). $\rho^{0}$ cells were prepared from a human osteocarcoma cell line 143B (ATCC CRL-8303) treated with ethidium bromide to deplete cytoplasmic mitochondrial DNA(kindly provided by Eric Shoubridge) [65]. Cells were grown to confluence in high glucose DMEM with pyruvate, L-glutamine, uridine (50 $\mu \mathrm{g} / \mathrm{ml}$ ) and 5\% FBS. At confluence cultures were harvested and DNA was extracted using QIAmp DNA Mini Kit.

\section{Amplification, cloning and sequencing}

Template from FFPE tissue samples and $\rho^{0}$ cells were amplified using 34 mitochondrial and 2 chromosome 17 primers. Using TaKaRa LA Taq DNA polymerase (Takara Bio Inc.), PCR reactions were performed using the following conditions: 1X LA PCR Buffer II ( $\mathrm{Mg}^{2+}$ plus), $0.4 \mathrm{mM}$ each dNTP mixture, 1X BSA (New England Biolabs Inc.), $0.6 \mu \mathrm{M}$ each primer, 1.25 Units LA Taq, 0.5\% Ficoll 400 and $1 \mathrm{mM}$ tartrazine (20,195-2, Aldrich). Total reaction volume was $25 \mu \mathrm{l}$. Cycling parameters were $94^{\circ} \mathrm{C}$ for 2 minutes, followed by 40 cycles of $94^{\circ} \mathrm{C}$ for 20 seconds, 30 seconds annealing at primer-specific optimized temperatures, and $72^{\circ} \mathrm{C}$ for 90 seconds. Cycling was performed on a DNA Engine Tetrad 2 (Bio-Rad, Hercules, CA). PCR products were purified, cloned and sequenced at $\mathrm{Lark}^{\mathrm{TM}}$ Technologies using in-house standard operating procedures (Houston, Texas). In general, 40 clones from each $\rho^{0}$ amplicon were selected and sequenced in both forward and reverse directions.

\section{Analysis}

Sequences were analyzed using the Phred-Phrap-Consed software package [66]. The sequences were then grouped based on similarity and a megaBLAST search of NCBI database was performed (using default parameters) to identify all the nuclear co-ordinates of the fragments. This enabled the chromosomal location and nuclear copy number of each amplicon to be determined. Pairwise sequence alignment was performed between the revised Cambridge Reference Sequence (rCRS)[67] and the $\rho^{0}$ clones from the suite of amplicons covering the entire mitochondrial genome using the Sequencher ${ }^{\mathrm{TM}}$ software(Gene Codes Corporation).

\section{Southern Blotting}

Mitochondrial genomes were cut with PvuII from 2 ug of total DNA extracted from normal blood and $\rho^{0}$ cells. Digested product was electrophoresed through a $0.4 \%$ agarose gel and blotted onto a membrane (Hybond- ${ }^{+}$, Roche Applied Sciences). Probes were generated from full length mtDNA (16.5 kb) by random primer labeling using the DIG System (Roche Diagnostics). Blots were incubated with probe, washed, blocked, incubated with anti-digoxigenin-AP fragments (Roche Applied Science) 
Table 3:

\begin{tabular}{|c|c|c|c|c|c|}
\hline Locus & Disease & Allele & Hom/Het & BLAST hits & Cloning data \\
\hline Leu & MM/CPEO & T3250C & $-/+$ & $C=16 ; A=1$ & $C=17$ \\
\hline Leu & CPEO & C3254T & $+/-$ & $T=18 ; A=2$ & $T=2,4$ and 17 \\
\hline Leu & MELAS & T329lC & $-/+$ & $C=17$ & $C=2,4$ and 17 \\
\hline NDI & NIDDM; LHON; PEO & G3316A & $+/-$ & $A=17$ & $A=2,4,16,17$ \\
\hline NDI & LHON & G3496T & $+/-$ & $T=14 ; A=2$ & $T=X, 2,4,16, \& 17$ \\
\hline NDI & MELAS & G3697A & $-/+$ & $A=3 ; C=1$ & $A=2 \& 4 ; G=X, 16,17$ \\
\hline \multirow[t]{2}{*}{ NDI } & Adult-Onset Dystonia & A3796G & $-/+$ & $\mathrm{G}=6$ & $A=2,4 \& 17 ; G=X \& 16$ \\
\hline & ADPD/Hearing Loss \& & & & & \\
\hline Gln & Migrane & T4336C & $+/+$ & $C=1$ & $C=17$ \\
\hline ND2 & $A D ; P D$ & G5460T/A & $+/+$ & $T=5 ; A=9$ & $\mathrm{G}=\mathrm{I}(2) ; \mathrm{T}=2$ \\
\hline Asn & CPEO/MM & G5703A & $-/+$ & $A=24$ & $A=17$ \\
\hline \multirow[t]{2}{*}{$\mathrm{COI}$} & PCA & G5913A & $+/-$ & $A=18 ; T=1$ & $G=I(2) ; A=17$ \\
\hline & Myogloinuria; Exercise & & & & \\
\hline $\mathrm{COI}$ & Intolerance & G5920A & $-/+$ & $A=0$ & $G=I(2) ; A=17$ \\
\hline $\mathrm{COI}$ & PCA & G5973A & $+/-$ & $A=3$ & $G=I(2) ; A=17$ \\
\hline $\mathrm{COI}$ & PCA & G608IA & $+/-$ & $A=1 ; T=1$ & $G=I(2) ; A=17$ \\
\hline Ser & MM/Exercise Intolerance & G7497A & $+/+$ & $A=14$ & $A=5$ \\
\hline ATP6 & LDYT & G8950A & $+/-$ & $A=2$ & $A=5$ \\
\hline ATP6 & Leigh Disease & T9185C & $-/+$ & $C=1$ & $C=5$ \\
\hline ND4 & MELAS & Allo84G & $+/+$ & $G=9$ & $G=9$ \\
\hline $\mathrm{His}$ & MICM & G12192A & $+/-$ & $A=9$ & $G=5(3) ; A=2(5)$ \\
\hline \multirow[t]{2}{*}{ ND5 } & LHON & GI3708A & $+/-$ & $A=15$ & $A=5 \& 9$ \\
\hline & Paracrystalline Inclusions & & & & \\
\hline CYTB & with Exercise Intolerance & GI5497A & $+/-$ & $A=2$ & $A=17$ \\
\hline \multirow[t]{2}{*}{ Thr } & Multiple Sclerosis & GI5927A & $+/-$ & $A=5$ & $G=5 ; A=17$ \\
\hline & Type 2 Diabetes; & & & & \\
\hline D-Loop & Cardiomyopathy & TI6I89C & $+/+$ & $C=0$ & $C=17$ \\
\hline
\end{tabular}

Hom: homoplasmy; Het: heteroplasmy;BLAST hits: number of times a unique numt nucleotide location was returned with a BLAST search; Cloning data: designates chromosome(s) location of nucleotide from cloning data; AD: Alzeimer's Disease; ADPD: Alzeimer's and Parkinson's Disease; PD: Parkinson's Disease; CPEO: Chronic Progressive External Opthalmoplegia; PEO: Progressive External Opthalmoplegia; LDYT: Leber's hereditary optic neuropathy and Dystonia; MELAS: Mitochondrial Encephalomyopathy, Lactic Acidosis and Stroke-like episodes; LHON: Leber's Hereditary Optic Neuropathy; MICM: Maternally Inherited Cardiomyopathy; MM: Mitochondrial Myopathy;NIDDM: Non-Insulin Dependent Diabetes; PCA: Prostate Cancer.

and reacted with a chemiluminescent substrate (CDPStar $^{\circledR}$ ) and exposed to X-ray film (Kodak) as recommended by the DIG Application Manual for Filter Hybridization (Roche Diagnostics, 2000).

\section{PCR}

For reverse transcriptase PCR analysis, total RNA was extracted from $\rho^{0}$ cells and a snap frozen skin sample using standard protocols outlined in the RNeasy Micro Kit manual (Qiagen). A DNase1 treatment step was included in the RNA extraction process to ensure the complete removal of all genomic DNA. We assessed RNA quantity and quality with the ND-1000 spectrophotometer (NanoDrop $^{\circledast}$ technologies) and by gel electrophoresis. First strand DNA was synthesized with the Omniscript ${ }^{\circledR}$ RT (Qiagen) kit. $2 \mathrm{ul}$ of the cDNA was amplified with primer sets to coding mitochondrial genes and a nuclear gene, 5aminolaevulinate synthase (hALAS) (Table 3), using the PCR conditions described above except the annealing temperature for these primers was $54^{\circ} \mathrm{C}$.
To examine for multiple copy numts, $50 \mathrm{ng}$ of genomic DNA from $\rho^{0}$ cells, blood and human placenta were amplified as described above, using primer sets to OXPHOS genes, .

\section{Authors' contributions}

RLP conceived of and supervised the study, and drafted the manuscript, JM, BR AA, and KR conducted experiments and participated in sequence alignment and data analysis, RW co-coordinated sample collection, GDD conducted experiments and helped draft the manuscript, JPJ provided intellectual insight and helped draft the manuscript, RET designed experiment and helped draft manuscript. All authors read and approved the final manuscript. 


\section{Additional material}

\section{Additional File 1}

Sequences of numt clones. The chromosomal locations and sequences of numts amplified using our primers

Click here for file

[http://www.biomedcentral.com/content/supplementary/14712164-7-185-S1.pdf]

\section{Acknowledgements}

We thank Eric Shoubridge for $\rho^{0}$ cells and Lark Technologies for cloning and sequencing. Financial support for this study was provided to Genesis Genomics Inc. by Industry Canada (FedNor), National Research CouncilIndustrial Research Assistance Program (NRC-IRAP), and Northern Ontario Heritage Fund Corporation (NOHFC).

\section{References}

I. Cavalli-Sforza LL: The DNA revolution in population genetics. Trends Genet 1998, 14(2):60-65.

2. Pakendorf B, Stoneking M: Mitochondrial DNA and Human Evolution. Annu Rev Genomics Hum Genet 2005.

3. Budowle B, Allard MW, Wilson MR, Chakraborty R: Forensics and mitochondrial DNA: applications, debates, and foundations. Annu Rev Genomics Hum Genet 2003, 4:I I9-I4I.

4. Parr RL, Dakubo GD, Thayer RE, McKenney K, Birch-Machin MA: Mitochondrial DNA as a potential tool for early cancer detection. Hum Genomics 2006, 2(4):252-257.

5. Fliss MS, Usadel H, Caballero OL, Wu L, Buta MR, Eleff SM, Jen J, Sidransky D: Facile detection of mitochondrial DNA mutations in tumors and bodily fluids. Science 2000, 287(5460):2017-2019.

6. Warburg O: On respiratory impairment in cancer cells. Science 1956, I 24(3215):269-270.

7. Carew JS, Huang P: Mitochondrial defects in cancer. Mol Cancer 2002, I(I):9.

8. Copeland WC, Wachsman JT, Johnson FM, Penta JS: Mitochondrial DNA alterations in cancer. Cancer Invest 2002, 20(4):557-569.

9. Penta JS, Johnson FM, Wachsman JT, Copeland WC: Mitochondrial DNA in human malignancy. Mutat Res 200I, 488(2): I 19-133.

10. Taylor RW, Turnbull DM: Mitochondrial DNA mutations in human disease. Nat Rev Genet 2005, 6(5):389-402.

II. Jakupciak JP, Wang W, Markowitz ME, Ally D, Coble M, Srivastava S, Maitra A, Barker PE, Sidransky D, O'Connell CD: Mitochondrial DNA as a cancer biomarker. J Mol Diagn 2005, 7(2):258-267.

12. O'Connell CD, Atha DH, Jakupciak JP: Standards for validation of cancer biomarkers. Cancer Biomarkers 2005, I:233-239.

13. Czarnecka AM, Golik P, Bartnik E: Mitochondrial DNA mutations in human neoplasia. J Appl Genet 2006, 47(I):67-78.

14. Lopez JV, Yuhki N, Masuda R, Modi W, O'Brien SJ: Numt, a recent transfer and tandem amplification of mitochondrial DNA to the nuclear genome of the domestic cat. J Mol Evol 1994, 39(2): 174-190.

15. Bensasson D, Feldman MW, Petrov DA: Rates of DNA duplication and mitochondrial DNA insertion in the human genome. J Mol Evol 2003, 57(3):343-354.

16. Parfait B, Rustin P, Munnich A, Rotig A: Co-amplification of nuclear pseudogenes and assessment of heteroplasmy of mitochondrial DNA mutations. Biochem Biophys Res Commun 1998, 247(I):57-59.

17. Davis RE, Miller S, Herrnstadt C, Ghosh SS, Fahy E, Shinobu LA, Galasko D, Thal LJ, Beal MF, Howell N, et al.: Mutations in mitochondrial cytochrome $c$ oxidase genes segregate with lateonset Alzheimer disease. Proc Natl Acad Sci USA 1997, 94(9):4526-453I.

18. Hirano M, Shtilbans A, Mayeux R, Davidson MM, DiMauro S, Knowles JA, Schon EA: Apparent mtDNA heteroplasmy in Alzheimer's disease patients and in normals due to PCR amplification of nucleus-embedded mtDNA pseudogenes. Proc Natl Acad Sci USA 1997, 94(26): I 4894-I 4899.
19. Davis JN 2nd, Parker WD Jr: Evidence that two reports of mtDNA cytochrome c oxidase "mutations" in Alzheimer's disease are based on nDNA pseudogenes of recent evolutionary origin. Biochem Biophys Res Commun 1998, 244(3):877-883.

20. Bandelt HJ, Salas A, Bravi C: Problems in FBI mtDNA database. Science 2004, 305(5689): I 402-I 404.

21. Yao YG, Bravi CM, Bandelt $\mathrm{HJ}$ : A call for mtDNA data quality control in forensic science. Forensic Sci Int 2004, I I I (I): I-6.

22. Salas A, Yao YG, Macaulay V, Vega A, Carracedo A, Bandelt HJ: A critical reassessment of the role of mitochondria in tumorigenesis. PLoS Med 2005, 2(I I):e296.

23. Salas A, Carracedo A, Macaulay V, Richards M, Bandelt HJ: A practical guide to mitochondrial DNA error prevention in clinical, forensic, and population genetics. Biochem Biophys Res Commun 2005, 335(3):89|-899.

24. Brandstatter A, Sanger T, Lutz-Bonengel S, Parson W, BeraudColomb E, Wen B, Kong QP, Bravi CM, Bandelt HJ: Phantom mutation hotspots in human mitochondrial DNA. Electrophoresis 2005, 26( I 8):34|4-3429.

25. Yao YG, Salas A, Bravi CM, Bandelt HJ: A reappraisal of complete mtDNA variation in East Asian families with hearing impairment. Hum Genet 2006.

26. Maitra A, Cohen Y, Gillespie SE, Mambo E, Fukushima N, Hoque MO, Shah N, Goggins M, Califano J, Sidransky D, et al.: The Human MitoChip: a high-throughput sequencing microarray for mitochondrial mutation detection. Genome Res 2004, I 4(5):8| 2-8|9.

27. Lynn S, Wardell T, Johnson MA, Chinnery PF, Daly ME, Walker M, Turnbull DM: Mitochondrial diabetes: investigation and identification of a novel mutation. Diabetes 1998, 47(I I): 1800-1802.

28. Dimauro S, Davidzon G: Mitochondrial DNA and disease. Ann Med 2005, 37(3):222-232.

29. White HE, Durston VJ, Seller A, Fratter C, Harvey JF, Cross NC: Accurate detection and quantitation of heteroplasmic mitochondrial point mutations by pyrosequencing. Genet Test 2005, 9(3): 190-199.

30. Wong L], Boles RG: Mitochondrial DNA analysis in clinical laboratory diagnostics. Clin Chim Acta 2005, 354(I-2): I-20.

31. Grzybowski T: Extremely high levels of human mitochondrial DNA heteroplasmy in single hair roots. Electrophoresis 2000 , 2I(3):548-553.

32. Swerdlow RH, Redpath GT, Binder DR, Davis JN 2nd, VandenBerg SR: Mitochondrial DNA depletion analysis by pseudogene ratioing. J Neurosci Methods 2006, I 50(2):265-27I.

33. Wu CW, Yin PH, Hung WY, Li AF, Li SH, Chi CW, Wei YH, Lee HC: Mitochondrial DNA mutations and mitochondrial DNA depletion in gastric cancer. Genes Chromosomes Cancer 2005, 44(I): 19-28.

34. Tseng LM, Yin PH, Chi CW, Hsu CY, Wu CW, Lee LM, Wei YH, Lee HC: Mitochondrial DNA mutations and mitochondrial DNA depletion in breast cancer. Genes Chromosomes Cancer 2006.

35. Higuchi M, Kudo T, Suzuki S, Evans TT, Sasaki R, Wada Y, Shirakawa T, Sawyer JR, Gotoh A: Mitochondrial DNA determines androgen dependence in prostate cancer cell lines. Oncogene 2006, 25(10): | $437-1445$.

36. Lee HC, Yin PH, Lin JC, Wu CC, Chen CY, Wu CW, Chi CW, Tam TN, Wei YH: Mitochondrial Genome Instability and mtDNA Depletion in Human Cancers. Ann N Y Acad Sci 2005, 1042: 109-122.

37. Satoh $M$, Kuroiwa $T$ : Organization of multiple nucleoids and DNA molecules in mitochondria of a human cell. Exp Cell Res 1991, 196(I): 137-140.

38. Cavelier L, Johannisson A, Gyllensten U: Analysis of mtDNA copy number and composition of single mitochondrial particles using flow cytometry and PCR. Exp Cell Res 2000, 259(I):79-85.

39. Robin ED, Wong R: Mitochondrial DNA molecules and virtual number of mitochondria per cell in mammalian cells. J Cell Physiol 1988, 136(3):507-513.

40. Greenwood AD, Paabo S: Nuclear insertion sequences of mitochondrial DNA predominate in hair but not in blood of elephants. Mol Ecol I999, 8(1): I33-137.

4I. Thalmann O, Hebler J, Poinar HN, Paabo S, Vigilant L: Unreliable mtDNA data due to nuclear insertions: a cautionary tale from analysis of humans and other great apes. Mol Ecol 2004, 13(2):32I-335.

42. Lorenz JG, Jackson WE, Beck JC, Hanner R: The problems and promise of DNA barcodes for species diagnosis of primate 
biomaterials. Philos Trans $R$ Soc Lond B Biol Sci 2005, 360(1462): I869-1877.

43. Parr RL, Dakubo GD, Crandall KA, Maki J, Reguly B, Aguirre A, Wittock R, Robinson K, Alexander JS, Birch-Machin MA, et al.: Somatic Mitochondrial DNA Mutations in Prostate Cancer and Normal Appearing Adjacent Glands in Comparison to AgeMatched Prostate Samples without Malignant Histology. J Mol Diagn 2006, 8(3):312-319.

44. Williams C, Ponten F, Moberg C, Soderkvist P, Uhlen M, Ponten J, Sitbon $G$, Lundeberg J: A high frequency of sequence alterations is due to formalin fixation of archival specimens. Am J Pathol 1999, I55(5): |467-|47|.

45. Srinivasan M, Sedmak D, Jewell S: Effect of fixatives and tissue processing on the content and integrity of nucleic acids. Am J Pathol 2002, I 6 I (6): | $96 \mid$ - | $97 \mid$.

46. Tourmen $\mathrm{Y}$, Baris O, Dessen P, Jacques C, Malthiery Y, Reynier P: Structure and chromosomal distribution of human mitochondrial pseudogenes. Genomics 2002, 80(I):71-77.

47. Ricchetti M, Tekaia F, Dujon B: Continued colonization of the human genome by mitochondrial DNA. PLoS Biol 2004, 2(9):E273

48. Richly E, Leister D: NUMTs in sequenced eukaryotic genomes. Mol Biol Evol 2004, 2 I (6): 108I- 1084.

49. Mishmar D, Ruiz-Pesini E, Brandon M, Wallace DC: Mitochondrial DNA-like sequences in the nucleus (NUMTs): insights into our African origins and the mechanism of foreign DNA integration. Hum Mutat 2004, 23(2): I 25-133.

50. Woischnik M, Moraes CT: Pattern of organization of human mitochondrial pseudogenes in the nuclear genome. Genome Res 2002, I 2(6):885-893.

5I. Collura RV, Auerbach MR, Stewart CB: A quick, direct method that can differentiate expressed mitochondrial genes from their nuclear pseudogenes. Curr Biol 1996, 6(1 0): I 337-1339.

52. Brandon MC, Lott MT, Nguyen KC, Spolim S, Navathe SB, Baldi P, Wallace DC: MITOMAP: a human mitochondrial genome database - 2004 update. Nucleic Acids Res 2005, 33(Database):D6|I-6|3

53. Fahy E, Nazarbaghi R, Zomorrodi M, Herrnstadt C, Parker WD, Davis RE, Ghosh SS: Multiplex fluorescence-based primer extension method for quantitative mutation analysis of mitochondrial DNA and its diagnostic application for Alzheimer's disease. Nucleic Acids Res 1997, 25(I 5):3 102-3109.

54. Wallace DC, Stugard C, Murdock D, Schurr T, Brown MD: Ancient $m$ tDNA sequences in the human nuclear genome: a potential source of errors in identifying pathogenic mutations. Proc Natl Acad Sci USA 1997, 94(26): I4900-I 4905.

55. Herrnstadt C, Clevenger W, Ghosh SS, Anderson C, Fahy E, Miller S, Howell N, Davis RE: A novel mitochondrial DNA-like sequence in the human nuclear genome. Genomics 1999, 60(1):67-77.

56. Woodward SR, Weyand NJ, Bunnell M: DNA sequence from Cretaceous period bone fragments. Science 1994 266(5 I 88): : $229-1232$.

57. Collura RV, Stewart CB: Insertions and duplications of $m$ tDNA in the nuclear genomes of Old World monkeys and hominoids. Nature 1995, 378(6556):485-489.

58. Taylor RW, Taylor GA Morris CM, Edwardson JM, Turnbull DM: Diagnosis of mitochondrial disease: assessment of mitochondrial DNA heteroplasmy in blood. Biochem Biophys Res Commun I 998, 25 I(3):883-887.

59. Goto $\mathrm{Y}$, Tojo M, Tohyama J, Horai S, Nonaka I: A novel point mutation in the mitochondrial tRNA(Leu)(UUR) gene in a family with mitochondrial myopathy. Ann Neurol 1992 3I(6):672-675.

60. Goto Y, Tsugane K, Tanabe Y, Nonaka I, Horai S: A new point mutation at nucleotide pair 329I of the mitochondrial tRNA(Leu(UUR)) gene in a patient with mitochondrial myopathy, encephalopathy, lactic acidosis, and stroke-like episodes (MELAS). Biochem Biophys Res Commun 1994, 202(3): $1624-1630$.

6I. Akanuma J, Muraki K, Komaki H, Nonaka I, Goto Y: Two pathogenic point mutations exist in the authentic mitochondrial genome, not in the nuclear pseudogene. J Hum Genet 2000 45(6):337-34I.

62. Petros JA, Baumann AK, Ruiz-Pesini E, Amin MB, Sun CQ, Hall J, Lim $\mathrm{S}$, Issa MM, Flanders WD, Hosseini $\mathrm{SH}$, et al.: mtDNA mutations increase tumorigenicity in prostate cancer. Proc Natl Acad Sci USA 2005, 102(3):719-724

63. Kosel S, Egensperger R, Mehraein P, Graeber MB: No association of mutations at nucleotide 5460 of mitochondrial NADH dehydrogenase with Alzheimer's disease. Biochem Biophys Res Commun 1994, 203(2):745-749.

64. Coskun PE, Beal MF, Wallace DC: Alzheimer's brains harbor somatic mtDNA control-region mutations that suppress mitochondrial transcription and replication. Proc Natl Acad Sci USA 2004, I 0 I(29): |0726-1073I.

65. King MP, Attardi G: Human cells lacking mtDNA: repopulation with exogenous mitochondria by complementation. Science 1989, 246(4929):500-503.

66. Nickerson DA, Tobe VO, Taylor SL: PolyPhred: automating the detection and genotyping of single nucleotide substitutions using fluorescence-based resequencing. Nucleic Acids Res 1997, 25(I4):2745-275I.

67. Andrews RM, Kubacka I, Chinnery PF, Lightowlers RN, Turnbull DM, Howell N: Reanalysis and revision of the Cambridge reference sequence for human mitochondrial DNA. Nat Genet 1999, 23(2): 147.
Publish with Biomed Central and every scientist can read your work free of charge

"BioMed Central will be the most significant development for disseminating the results of biomedical research in our lifetime. "

Sir Paul Nurse, Cancer Research UK

Your research papers will be:

- available free of charge to the entire biomedical community

- peer reviewed and published immediately upon acceptance

- cited in PubMed and archived on PubMed Central

- yours - you keep the copyright 